\title{
Money or morality: fairness ideals in unstructured bargaining
}

\author{
Wolfgang J. Luhan ${ }^{1} \cdot$ Odile Poulsen ${ }^{2} \cdot$ Michael W. M. Roos ${ }^{3}$
}

Received: 21 April 2016 / Accepted: 19 July 2019 / Published online: 31 July 2019

(c) The Author(s) 2019

\begin{abstract}
We augment the Nash bargaining solution by fairness ideals in order to predict the outcomes of unstructured bargaining after the individual production of a joint surplus. If production depends on individual effort, talent, and luck, fairness ideals might be based on the accountability principle. In a lab experiment with real production and unstructured bargaining, we investigate subjects' fairness ideals, their bargaining behaviour, and the outcomes of the bargaining process. As impartial spectators, about $75 \%$ of the subjects hold meritocratic or libertarian fairness ideals. However, these ideals do not affect their bargaining behaviour which is strongly opportunistic. Therefore the fairness-augmented Nash solution with opportunistic fairness ideals predicts the bargaining outcome best.
\end{abstract}

\section{Introduction}

Most bargaining proceeds in an unstructured way. In many cases, for instance when at least one bargaining partner is not a professional or when the partners meet for the first time or never again in the future, there are no institutions that determine when the partners can make offers or that mandate that new offers must always be more generous to the partner than previous ones. The Nash bargaining solution (Nash 1950) is the standard model to predict the outcome of unstructured bargaining processes, even though the Nash model does not describe the bargaining process. According to the Nash bargaining solution, the bargaining outcome depends on the bargaining

Luhan and Roos would like to dedicate this article to their friend and coauthor Odile Poulsen, who sadly passed away before the publication. Odile was a good friend and an inspirational colleague and she will be deeply missed by all who knew her.

Electronic supplementary material The online version of this article (https://doi.org/10.1007/s00355019-01206-5) contains supplementary material, which is available to authorized users.

Wolfgang J. Luhan

wolfgang.luhan@port.ac.uk

Extended author information available on the last page of the article 
power of the two partners and the utility of their outside options. With equal bargaining power and identical outside options the Nash solution is the 50:50 split of the total surplus.

However, in addition to bargaining power and outside options, claims on the joint surplus may have an impact on the final distribution. Such claims may naturally arise if the partners contributed to the production of the joint surplus. This view is supported by the growing literature on bargaining with joint production (see Karagözoğlu 2012). Here a joint pie to be distributed is produced individually by the agents. Cappelen et al. $(2007,2010,2011)$ made an important contribution to the experimental literature showing that the 50:50 split frequently observed in ultimatum and dictator games without production is less frequent in experiments in which the surplus was endogenously produced. These authors argue that if the payoff to be distributed was produced by the bargaining parties instead of exogenously given to the players like "manna from heaven" fairness considerations come into play.

This paper shows how fairness considerations can be incorporated into the Nash bargaining model and that this fairness-augmented Nash bargaining model can predict the outcomes of an unstructured bargaining game with previous production. We implement an economic laboratory experiment in which subjects produce a joint surplus in a real-effort task and negotiate on how to divide it according to an unstructured bargaining protocol in groups of two.

We focus on fairness ideals that can be justified by a theory of distributive justice (Konow 2003) rather than those derived from pro-social preferences (e.g. Fehr and Schmidt 1999; Bolton and Ockenfels 2000), which do not capture the idea that fairness does not only depend on the final distribution of some surplus, but also how this surplus was generated in the first place. A very common conception of fairness is the equity principle according to which a fair allocation requires a relation (such as proportionality) between the inputs (or contributions) of the partners and their final payoffs (see Konow 2003). As a refinement of the equity principle Konow (1996) introduces the accountability principle which requires that a person's fair allocation is proportional to the variables which can be controlled such as personal effort. We investigate whether the subjects in our experiment make fairness judgments based on the accountability principle and whether these judgments can be used to predict the outcomes of the unstructured bargaining process.

Fairness ideals based on the accountability principle could affect bargaining in several different ways. On the one hand, subjects might derive utility from allocations they consider as fair from an impartial spectator's perspective, i.e. independent of whether they have a stake in the bargaining or not. In this case, we would expect a close correlation between fairness ideals and bargaining offers. On the other hand, it is well known that bargainers are often subject to a self-serving bias (e.g. Babcock and Loewenstein 1997; Konow 2000), which distorts their fairness judgments and their behaviour in the direction of their own self-interest. Subjects might use fairness arguments to justify their offers, but those arguments and the resulting offers may have little to do with their "true" convictions as impartial spectators.

Our paper is related to Cappelen et al. (2007, 2010, 2011), but while these authors use the dictator game in their experiments we focus on how fairness considerations affect economic behaviour in unstructured bargaining situations. This difference is 
important, because the distribution of power is fundamentally different in the dictator game and in unstructured bargaining. With all the power on the side of the dictator and equal bargaining power in our unstructured bargaining protocol, our experiment and the experiments of Cappelen et al. lie at the opposite ends of the spectrum of bargaining power distribution.

The distribution of bargaining power may matter for the role of fairness in the bargaining process, since it could influence the self-serving bias discussed above. Rustichini and Villeval (2014) argue that moral hypocrisy, which they define as the motivation to appear moral without acting according to the moral prescriptions, depends on power and strategic considerations. They show that the stronger side in a bargaining bends the norm in his or her favour and the weak side agrees. Moral hypocrisy is larger in games where real choices have no strategic consequence than in those where they do. Both findings would suggest that we should observe more self-serving behaviour in a dictator game than in unstructured bargaining, since in the latter situation both partners have equal power and their behaviour may have strategic consequences. However, the converse might also be true. One can hypothesize that subjects will be less fair and display more moral hypocrisy in unstructured bargaining than in dictator games, because they have more "moral wiggle room". As Dana et al. (2007) show, many subjects behave fairly in dictator games without actually valuing the fair outcome, because they feel compelled to do so. In an unstructured bargaining situation, in which both partners have equal bargaining power, this perceived moral obligation may be much weaker, since each player is equally responsible for the final allocation. Hence subjects can make more selfish offers than they would in dictator games with the justification that their bargaining partner is not forced to accept them. If the bargaining partner does indeed accept any unfair offers, the proposer can shift the responsibility to the partner.

Our paper is also related to Gächter and Riedl $(2005,2006)$ and Karagözoğlu and Riedl (2014) who also analyse unstructured bargaining. However, besides several technical differences between their designs and ours, ${ }^{1}$ these authors study the effect of infeasible claims on bargaining using different distributional norms (which are normative solution concepts to bargaining problems with infeasible claims) than the ones we consider.

To investigate the effect fairness ideals have on the bargaining behaviour of our subjects, we administered both a pre- and a post-experimental questionnaire. In the pre-experimental questionnaire we find that none of our subjects consider the "classical" 50:50 split as fair, but roughly $75 \%$ of the subjects hold meritocratic or libertarian fairness ideals. These ideals, however, hardly affect subjects' bargaining behaviour. The observed offers are very opportunistic, with high performers making libertarian offers and low performers claiming more than their contribution. We demonstrate that the standard Nash bargaining solution can be adjusted to incorporate fairness in a theoretical model. We find that the fairness-augmented Nash solution incorporating opportunistic fairness ideals is able to predict $96 \%$ of the variation in the accepted

\footnotetext{
1 While the unstructured bargaining procedure in these papers and ours is fairly similar, the real effort production phases are different. In these papers, subjects participate in general knowledge quizzes, while we implement a number counting task, a brainteaser, and a coin toss. These more diverse tasks are necessary to clearly distinguish between the fairness types described in Sect. 2.
} 
offers. This approach is related to Birkeland and Tungodden (2014) who show theoretically that bargaining can end in disagreement if individuals are fairness minded and have incompatible fairness views. They also use the Nash bargaining solution to show theoretically how the nature of the bargaining agreement depends on the potentially different fairness preferences of the bargaining parties. In contrast to our paper, Birkeland and Tungodden (2014) do not analyze the specific fairness ideals that bagainers holds and how much they actually act upon these ideals.

The paper is structured as follows. Section 2 contains the fairness-augmented Nash model that we propose to predict the outcomes of unstructured bargaining after individual production. Section 3 describes the experimental design and procedures and Sect. 4 presents the results. We conclude in Sect. 5.

\section{Theory and research questions}

We use the Nash bargaining solution from cooperative game theory to predict the outcome of unstructured bargaining. In a similar vein to Birkeland and Tungodden (2014), we modify the standard Nash bargaining solution by taking into account that individuals might care about fairness and get disutility if their share of the surplus falls short of what they consider fair.

We assume that each individual's outside option is equal to zero. Taking fairness ideals into account, we argue that the Nash bargaining solution can be found by solving

$$
\begin{gathered}
\max _{x_{i}, x_{k}}\left(x_{i}-\mu_{i} x_{i}^{f}\right)^{\phi_{i}}\left(x_{k}-\mu_{k} x_{k}^{f}\right)^{\phi_{k}} \\
\text { s.t. } Y \geq x_{i}+x_{k}
\end{gathered}
$$

where the parameter $\phi_{i, k}$ determines the bargaining power of individual $i$ or $k$, and $\mu_{i, k}$ is a discount factor; $\phi_{i}, \mu_{i} \in[0,1]$ and $Y$ is the total available surplus of two partners. Different bargaining power might stem from different degrees of risk aversion. $x_{i, k}$ is the monetary payoff that individual $i$ or $k$ receives after the bargaining and $x_{i}^{f}$ is the own payoff that $i$ perceives as fair. $x_{i}^{f}$ might correspond to some fairness ideal that individuals would implement as impartial spectators. In a cooperative bargaining situation with conflict of interest, however, it is in general not possible for either bargaining partner to fully achieve their own fairness ideals. Each bargainer's ideal must therefore be discounted by a factor $\mu_{i}$ that defines the minimum payoff that individual $i$ can just accept as "fair enough". If $x_{i}<\mu_{i} x_{i}^{f}$ individual $i$ regards the allocation as unfair and would get a negative utility from accepting it. $\mu_{i} x_{i}^{f}$ is hence not an outside option as in the conventional model, but rather a reference point. The Nash bargaining solution is

$$
\begin{aligned}
& x_{i}=\frac{\phi_{i}}{\phi_{i}+\phi_{k}} Y+\frac{\phi_{k}}{\phi_{i}+\phi_{k}} \mu_{i} x_{i}^{f}-\frac{\phi_{i}}{\phi_{i}+\phi_{k}} \mu_{k} x_{k}^{f} \\
& x_{k}=\frac{\phi_{k}}{\phi_{i}+\phi_{k}} Y+\frac{\phi_{i}}{\phi_{i}+\phi_{k}} \mu_{k} x_{k}^{f}-\frac{\phi_{k}}{\phi_{i}+\phi_{k}} \mu_{i} x_{i}^{f}
\end{aligned}
$$


The parameter $\phi_{i}$ determines the bargaining power of individual $i$. If $\phi_{i}>\phi_{k}$ individual $i$ has more bargaining power than individual $k$ which, in our case, could be the case if individual $i$ was less risk averse than individual $k$. This is evident if $x_{i}^{f}=x_{k}^{f}=0$, because then the share of $Y$ that individual $i$ receives is larger than the share of individual $k, \frac{\phi_{i}}{\phi_{i}+\phi_{k}}>\frac{\phi_{k}}{\phi_{i}+\phi_{k}}$. On the other hand, if individuals have identical bargaining power and discount their fairness ideal in the same way, ${ }^{2}$ the Nash solution is the average of the total surplus and the difference of what partners would like to get for themselves:

$$
\begin{aligned}
& x_{\mathrm{i}}=0.5 Y+0.5 \mu\left(x_{\mathrm{i}}^{f}-x_{\mathrm{k}}^{f}\right) \\
& x_{\mathrm{k}}=0.5 Y+0.5 \mu\left(x_{\mathrm{k}}^{f}-x_{\mathrm{i}}^{f}\right)
\end{aligned}
$$

The main challenge is to determine which offers are perceived as fair, $x_{i}^{f}$, and by how much individuals are willing to deviate from the fairness ideal, which is captured by $\mu$.

In order to formalize the fairness ideals, we follow Cappelen et al. (2010) who propose four fairness ideals derived from a theory of justice based on responsibility (see Konow 1996, 2001, 2003). The four fairness ideals differ by the so called responsibility cut, which defines the factors that individuals should or should not be held responsible for. One extreme view is that responsibility does not matter and the equal distribution of resources is fairest. This ideal is called egalitarianism. The other extreme case is libertarianism according to which every individual is fully responsible for his own fate or income, even for factors beyond individual control. The distributional prescription of libertarianism is that every individual deserves what he or she can earn and that no redistribution of income should take place. There are two intermediate cases in which subjects are responsible for some factors of their income, but not for others. Choice egalitarianism says that one is responsible for factors under direct control, such as effort, whereas meritocratism also includes personal traits or merits. Cappelen et al. (2010) use a proportional rule to derive the fair distributions according to the different ideals. Proportionality refers to a situation where each agent's share of the final outcome corresponds to the share of production the respective agent is responsible for. We believe, however, that a proportional rule is less intuitive and easy to apply than a linear rule that we adopt in this paper. A simple yet plausible rule would be that each participant is entitled to a certain fraction of the pie and the remaining amount is split equally. This rule is analogous to the so-called Talmud rule (see Aumann and Maschler 1985; Gächter and Riedl 2005) that applies to bankruptcy problems in which not all claims of all debtors can be satisfied. Following this approach, we translate the fairness ideals into a linear rule. A distribution is fair if each partner receives the total amount of income for which he is responsible and the remainder is shared equally. We chose this simpler rule to make it easier for the participants in our experiment to

\footnotetext{
2 In the following, we assume identical individuals. We test this assumption in the empirical part of the paper, where we will not only determine the fairness ideals of our participants (Sect. 4.1) but also estimate the accepted deviation from the fair share, $\mu$, and measure the differing bargaining powers $\phi$ (Sect. 4.2).
} 
Table 1 Weights on income sources according to different fairness ideals

Theoretical weights for the income components in Eq. (7)

\begin{tabular}{lllllll}
\hline & $\mathrm{Y}_{\mathrm{i}}^{\text {effort }}$ & $\mathrm{Y}_{\mathrm{i}}^{\text {talent }}$ & $\mathrm{Y}_{\mathrm{i}}^{\text {luck }}$ & $\mathrm{Y}_{\mathrm{k}}^{\text {effort }}$ & $\mathrm{Y}_{\mathrm{k}}^{\text {talent }}$ & $\mathrm{Y}_{\mathrm{k}}^{\text {luck }}$ \\
\hline Egalitarian & 0.5 & 0.5 & 0.5 & 0.5 & 0.5 & 0.5 \\
$\begin{array}{l}\text { Choice } \\
\text { egalitarian }\end{array}$ & 1 & 0.5 & 0.5 & 0 & 0.5 & 0.5 \\
Meritocratic & 1 & 1 & 0.5 & 0 & 0 & 0.5 \\
Libertarian & 1 & 1 & 1 & 0 & 0 & 0 \\
\hline
\end{tabular}

find a fair distribution when faced with a surplus defined by six numbers - both group members' earnings from the three tasks.

To formalise this linear rule, we assume that individual income $Y_{i}$ was produced with the factors effort, talent, and luck. Combine the incomes of two individuals $i, k$, and let $x_{i}^{f}$ represent the fair offer of individual $i$ as a function of $i$ 's income components and the ones of the other individual $k$, that in sum constitute the overall surplus $\left(Y=Y_{i}+Y_{k}\right)$. We get

$x_{i}^{f}=\eta Y_{i}^{\text {effort }}+\tau Y_{i}^{\text {talent }}+\lambda Y_{i}^{\text {luck }}+(1-\eta) Y_{k}^{\text {effort }}+(1-\tau) Y_{k}^{\text {talent }}+(1-\lambda) Y_{k}^{\text {luck }}$

The four different fairness ideal can be captured by different weights in this function, which can have the values $0,0.5$, or 1 (see Table 1 ). According to the egalitarian ideal, one has, $\eta=\tau=\lambda=0.5$, implying that individual $i$ can claim half of all income components. A choice egalitarian would claim all of his income from effort, $\eta=1$, and none of the other individuals' effort income, $1-\eta=0$ and the income resulting from talent and luck is shared, $\tau=\lambda=0.5$. Meritocrats also claim their full income from talent and libertarians have $\eta=\tau=\lambda=1$.

The Talmud and the proportionality rules result in different surplus allocations only for subjects with either choice egalitarian or meritocratic ideals who have to split a surplus. ${ }^{3}$ To see this, consider two players with choice egalitarian fairness ideals. If they follow the Talmud rule, each subject would claim their total effort contribution, grant their partner their total share of the effort contribution of the same surplus, and expect that the talent and luck contributions be split equally between her and her partner. In contrast, if both subject uses the same proportionality rule as in Cappelen et al. (2010), each subject would only claim their proportional share of the total effort contribution to the total surplus.

It is well known from the literature that fairness judgments tend to be biased in the direction of self-interest if the persons who make the judgments have stakes in the situation to be evaluated (see, e.g., Babcock and Loewenstein 1997; Konow 2000, 2001). Konow (2000) argues that people often resolve the tension between material self-interest and maintained fairness ideals by self-deception, i.e. by adjusting their beliefs about what is fair in a self-serving manner.

\footnotetext{
3 For the egalitarian ideal the only feasible choice is fifty-fifty, and for the libertarian ideal the only feasible split is that each subject gets their own contribution. So for egalitarianism and libertarianism both the proportionality and Talmud rules result in the same distributions.
} 
Our main research question is whether the outcome of an unstructured bargaining process after a production phase can be predicted by the fairness-augmented Nash bargaining solution. In order to answer this question we must identify which fairness ideals people hold and how these fairness ideals affect the bargaining behaviour. In particular, we analyse whether individuals maintain the same fairness ideals before, during, and after the bargaining, or whether we can observe an adjustment of the fairness ideals potentially caused by an effort to reduce cognitive dissonance. Finally, we ask how much individuals on average are willing to concede in the bargaining process relative to what they perceive as the "fair offer". In other words, we estimate the average percentage $\mu$ of the targeted fair offer that individuals just accept as still fair.

\section{Experimental design and procedure}

Our experimental protocol consists of four parts: a pre-experimental questionnaire with which we elicit subjects' normative judgements, a real-effort production phase in which subjects individually generate a monetary surplus, a bargaining phase in which pairs of subjects distribute their endowments in an unstructured bargaining protocol, and a post-experimental questionnaire similar to the pre-experimental questionnaire. We also elicited personal details such as age, gender, and field of study after the experiment. ${ }^{4}$

The pre-experimental questionnaire ${ }^{5}$ consisted of seven questions, each presenting a hypothetical distribution of a joint surplus between two hypothetical persons, A and B. Subjects were informed that this surplus had been produced by a combination of talent, effort and luck. The individual contributions of A and B were shown in a table, and each subject knew the extent to which A and B's surplus was generated by talent, effort and luck. The first four questions were open choice questions. Here subjects had to specify a fair division of the surplus between A and B. The remaining three questions were in a "multiple choice" format. Here subjects had to choose one fair distribution of the surplus between A and B from a list of possible distributions. The distributions were given in a table, and subjects could again see how much A and B each had contributed to the joint surplus in the talent, effort and luck stages. Each proposed distribution in the list corresponded to one of the fairness ideals we are interested in, i.e. meritocratism, choice egalitarianism, egalitarianism and libertarianism, calculated by the formula given in the previous section. ${ }^{6}$ The numbers of the contributions of the hypothetical persons A and B were chosen such that the four fairness ideals demanded different distributions. The post-experimental questionnaire was shorter

\footnotetext{
4 As the exposure to a questionnaire might have an impact on subjects' behavior in subsequent experiments, we implemented a control treatment without the pre-experimental questionnaire. We did not find any significant effects on behavior and therefore only report the observations from the treatments including the pre-experimental questionnaire.

5 The instructions as well as the questionnaires can be found in Online Appendix A.

6 We also presented the choice egalitarian and the meritocratic offers calculated with a proportional rule as an alternative to the way we capture the fair distributions. These distributions based on the proportional rules were almost never chosen so that we did not take them into account in the analysis.
} 
and consisted only of one open-choice question (Q1) and one multiple-choice question (Q6). The questionnaires were not incentivized. Importantly, subjects received the pre-experimental questionnaire before they were informed about the nature of the subsequent experiment. We used open questions to elicit the fairness beliefs of our subjects without being influenced by possible options. The multiple choice questions were designed to allow for a more rigid prediction of the subjects' fairness ideals in case the open questions would be inconclusive. We find that the answers in both parts of the questionnaires (multiple-choice and open questions) were highly coherent and we therefore use both to determine the fairness ideals (see the Sect. 4).

In the first part of the experiment (production phase), participants had to produce a surplus in three different ways during three distinct stages. In the first stage of the production phase participants had to answer a twenty-question IQ test-like quiz (taken from Hesse and Schrader 2009). The first stage lasted fifteen minutes. The contribution of each participant in this phase was then labelled "brainteaser". In the next stage of the production phase, participants had to take part in a real-effort task consisting of counting ones in rows of zeros and ones on a screen. There was a maximum of 60 screens during fifteen minutes. With each counting screen came the possibility to exit the production phase by pressing a button. Contributions of each participant in this stage were labelled "counting". For each of the first two stages of the production phase, high performers in the top tercile of the session received twelve euros, middle performers received eight euros, and low performers in the bottom tercile received five euros credited on an account. The third and final stage of the production phase was a coin toss, and was labelled "coin toss". In this stage a participant was chosen randomly to toss a coin in front of the other participants. At the beginning of the experiment all participants had been randomly assigned to an H-group and a T-group. If the coin fell on head, then all participants in group $\mathrm{H}$ received three euros, if it fell on tail, then the other group earned three euros. ${ }^{7}$

Upon completion of the first part of the experiment participants received instructions for the second part that were again read aloud. Any questions were answered privately. This second part of the experiment was the bargaining phase. The subjects were matched randomly with a partner. When a match was formed each of the surpluses generated by the two participants (produced during the production phase) were put on a joint surplus account. Subjects were informed about their own earnings from the talent, effort, and luck tasks as well about the earnings of the partner (see Fig. 1). Matched participants then bargained for $5 \mathrm{~min}$ about how to divide the joint surplus. The bargaining was unstructured: each subject could propose a distribution, and could respond to a proposal made by the other subject, at any time. To make an offer a subject entered a claim for himself and the computer calculated the remainder to the partner (participants just had to press a "calculate" button to see this remainder), such that proposed divisions were feasible and efficient by design, and no resources were wasted. After the proposing subject confirmed an offer, the offer became visible in an

\footnotetext{
7 As in all experimental procedures, the order of the stages in the production phase might play a role. However, as we focus purely on the impact of fairness ideals in the bargaining process, these effects are irrelevant for our study. As long as the link between performance and resulting surplus is comprehensible and credible to the subjects, we are confident that possible order effects in the production phase can be disregarded.
} 


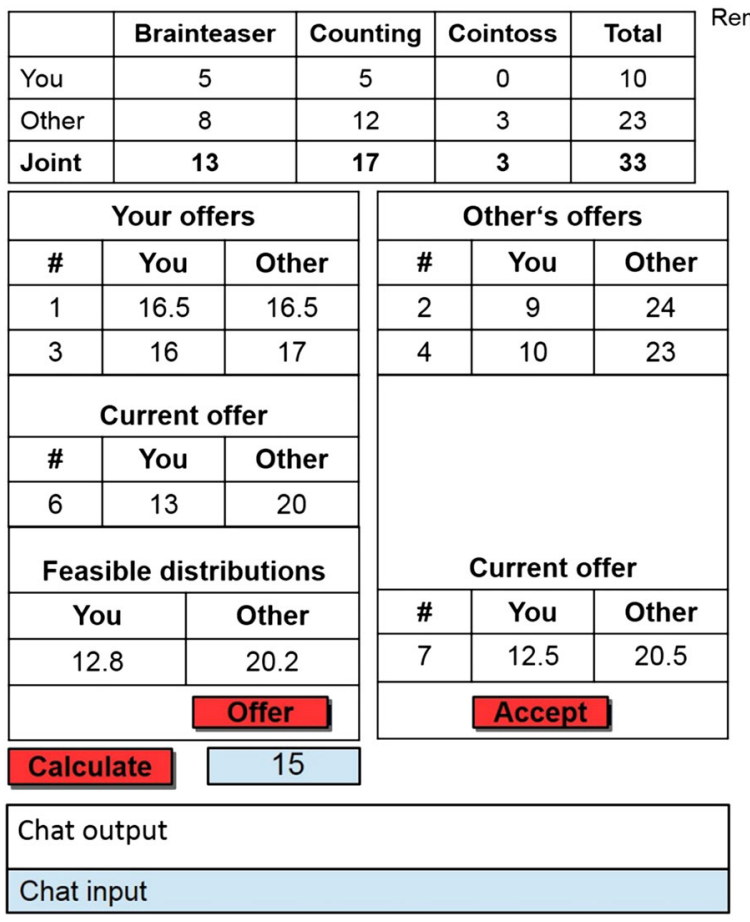

Fig. 1 Bargaining screen

offer table both for the proposer and the partner and was labelled current offer. The partner could respond by either accepting the current offer, making a counter offer, or doing nothing. At any time each subject could make a new offer, which replaced the old current offer. Only current offers could be accepted, but there were no restrictions on posting identical offers several times. New offers were added to the table of offers so that the complete history of offers was visible all the time. If an offer was accepted, the round ended and the distribution was recorded. If the bargaining time was over without any of the subjects accepting the partner's current offer, both subjects received a payoff of zero for this round.

We used a five-period perfect stranger re-matching protocol. Only one of the five bargaining rounds was randomly chosen for the final monetary payoff in order to avoid carry-over effects between the rounds. During the bargaining, subjects could send unrestricted messages to each other using a chat function. ${ }^{8}$

The computerized experiment was implemented at the RUB $\varepsilon \chi$ lab at the RuhrUniversity Bochum (Germany), using the experimental software z-Tree (Fischbacher 2007). 72 students from all disciplines participated in 5 sessions. Approximately $40 \%$ of participants were female, and about $50 \%$ of the participants were eco-

\footnotetext{
8 Subjects were not allowed to reveal their identities or to threaten or insult their respective partners. The chats were monitored such that violators could have been expelled from the experiment (which never happened).
} 
nomics/management students. Sessions lasted roughly $2 \mathrm{~h}$ and the average payoff was $€ 21.43$, including a show-up fee of $€ 4$. ${ }^{9}$

Upon arrival participants were seated in separate cubicles and allocated randomly into two groups, $\mathrm{H}$ and $\mathrm{T}$. Each session started with instructions for the main part of the experiment (provided in the Online Appendix). At this stage it was made clear that there would be additional parts of the experiments, but that the instructions for these parts would only be handed out after the completion of the current part. Participants received written instructions (see the Online Appendix), which were read aloud to ensure common knowledge. Everybody had the opportunity to ask questions in private.

\section{Results}

Since the focus of our paper lies on the effects of fairness ideals in the bargaining process, we start our analysis with the classification of our subjects' fairness ideals. In Subsection 4.1, we first present the fairness ideals of subjects as impartial spectators that we elicited using the questionnaires. In the next step, we analyse how subjects' offers in the bargaining stage are related to the elicited fairness ideals. This analysis serves to determine the fair allocations in the fairness-augmented Nash model that we apply and test in Sect. 4.2.

\subsection{Fairness ideals}

\subsubsection{Classification of subjects}

We use the data from the pre- and post-experimental questionnaires to classify subjects according to the fairness ideal that best fit their answers. Since not all subjects give answers that are consistent with a unique fairness ideal across the different questions, we compute the distance between the chosen hypothetical allocations and the ones predicted by the fairness ideals. For each of the questions Q1 to Q4, and each fairness ideal, $j$, define the fairness index $F_{i q}^{j}=1-\left|m_{A q}-f_{A q}\right| / f_{A q}$, where $m_{\mathrm{Aq}}$ is the amount of money subject $i$ would give to person $\mathrm{A}$ in question $q$ and $f_{A q}$ is the amount that person A should receive according to the corresponding fairness ideal (egalitarian, choice egalitarian, meritocratic, libertarian). In questions Q5-Q7 subjects had to choose one distribution among a list of distributions, each of which reflected a different fairness ideal. For these questions $F_{i q}^{j}$ was given the value 1, if the respective fairness ideal was chosen, and 0 otherwise as the given answer in these questions would reflect one fairness ideal only. Each individual was then assigned an overall index for each ideal $j, F_{i}^{j}=\frac{F_{i 1}^{j}+F_{i 2}^{j}+\cdots+F_{i 7}^{j}}{7}$. By construction, $F_{i}^{j}=1$ if a subject's answers consistently ${ }^{10}$ and perfectly reflect one fairness ideal $j$.

\footnotetext{
9 We labelled the show-up fee as a payment for filling in the questionnaire(s).

10 The average fairness ideal index $F^{j}$ is 0.81 , which roughly means that the answers in the questionnaire on average deviate by $19 \%$ from the fairness ideal that describes them best. One might argue that if subjects give very inconsistent answers, the classification of subjects into fairness types is prone to large measurement
} 
Table 2 Classification of subjects based on questionnaire responses

\begin{tabular}{|c|c|c|c|c|c|}
\hline \multirow[t]{2}{*}{ Shares } & \multicolumn{5}{|c|}{ Post-experimental questionnaire } \\
\hline & Egalitarian & Choice egalitarian & Meritocratic & Libertarian & Total pre \\
\hline \multicolumn{6}{|l|}{$\begin{array}{l}\text { Pre-experimental } \\
\text { questionnaire }\end{array}$} \\
\hline Egalitarian & $0.0 \%(0)$ & $0.0 \%(0)$ & $0.0 \%(0)$ & $0.0 \%(0)$ & $0.0 \%(0)$ \\
\hline Choice egalitarian & $1.4 \%(1)$ & $8.3 \%(6)$ & $9.7 \%(7)$ & $6.9 \%(5)$ & $26.4 \%(19)$ \\
\hline Meritocratic & $6.9 \%(5)$ & $2.8 \%(2)$ & $18.1 \%(13)$ & $16.7 \%(12)$ & $44.4 \%(32)$ \\
\hline Libertarian & $1.4 \%(1)$ & $0.0 \%(0)$ & $6.9 \%(5)$ & $20.8 \%(15)$ & $29.2 \%(21)$ \\
\hline Total post & $9.7 \%(7)$ & $11.1 \%(8)$ & $34.7 \%(25)$ & $44.4(32)$ & $100.0 \%(72)$ \\
\hline
\end{tabular}

The pre- and the post-experimental questionnaires were implemented before or after the experimental decisions respectively. The numbers in parenthesis are absolute frequencies

Table 2 cross-tabulates how subjects are classified according to the pre- and the post-experimental questionnaires. The diagonal of Table 2 shows that 34 out of 72 subjects $(47.2 \%)$ are assigned the same type by the pre- and the post-experimental questionnaire. Of those 34 subjects 15 are classified as libertarians (44.1\%), 13 as meritocrats $(38.2 \%)$, and 6 as choice egalitarians (17.6\%). When asked before the experiment, no subject gave egalitarian answers. Confirming Cappelen et al. (2007, 2011) and Cappelen et al. (2010) the egalitarian distribution is not perceived as fair by our subjects if the individual contributions to the joint surplus are known. The number of egalitarian subjects went up from 0 to 7 after the experiment, which is a statistically significant increase to $9.7 \%\left(\mathrm{p}=0.023\right.$, McNemar test). ${ }^{11}$ The fraction of choice egalitarians dropped significantly from $26.4 \%$ before the experiment to $11.1 \%$ after the experiment $(\mathrm{p}=0.0098)$. The share of libertarians increases from $29.2 \%$ to $44.4 \%(\mathrm{p}=0.037)$, while the shares of meritocrats are not statistically different before and after the experiment at the $10 \%$ level. $^{12}$

\subsubsection{Classification of offers}

In the next step we want to see how the fairness ideals elicited in the questionnaire translate into bargaining behaviour. ${ }^{13}$

\section{Footnote 10 continued}

errors. We checked whether this argument is relevant for our subsequent analysis by dividing all subjects into a consistent group and an inconsistent group defined by the median value of $F^{j}$ which is equal to 0.806 . Analysing the bargaining behaviour of the subjects whose type is less (more) precisely measured, because their $F^{j}$ is below (above) the median, does not change any of our conclusions.

11 We use the McNemar test (Edwards correction) for changes over time in a sample in for all tests relating to the frequencies in Table 2 . A $\chi^{2}$ test yields qualitatively similar results.

12 The differences between the pre- and post-experimental questionnaires do not stem from the differences in the number of questions asked. We implemented the same analysis using only Q1 and Q6 from both questionnaires finding similar results. The results for this additional analysis can be found in table B 1 in Online Appendix B.

13 As an anonymous referee has correctly pointed out, an important assumption when comparing the survey responses to the offers in the bargaining process is that the production tasks are perceived to be reflecting effort, talent and luck. We implemented a separate survey analysis confirming that this is indeed the case. 
We use the term "offers" for proposed distributions. Each offer in the bargaining process consists of a claim for the proposer himself and a proposal for the other player. In the analysis, we use the offers as the dependent variable, since by design all offers are efficient and exhaust the total available surplus. Remember that each offer can be accepted by the partner and is therefore binding. We use all offers made as our main analytical tool. However, two sources of bias might be relevant. Firstly, bargainers might strategically deviate from their fairness ideal if they expect their bargaining partners to hold a different fairness ideal, making higher or lower offers than what they actually desire. This should only play a minor role in our setting as bargainers face the risk of an immediate acceptance of any offer posted. Secondly, all but the initial offers might deviate from the true fairness ideal as they could be a response to the offers of the partner, which reflect his fairness ideal. Later offers are, quite naturally, influenced by both bargainers' fairness ideals. We therefore performed most of our analyses not only using all, but also using only the first and only the last (accepted) offers, mostly without changing our results and definitely without any impact on our conclusions.

In each bargaining situation, we can predict what the offer should be depending on the four fairness types. Each actual offer can then be assessed using the squared distance from the different fair offers. We classify each offer as (choice) egalitarian, meritocratic or libertarian if it has the minimum squared distance to the predicted offer based on the respective fairness ideal. Table 3 summarizes the results of the offer classification. Of all offers, $28.9 \%$ are egalitarian, $27.9 \%$ are choice egalitarian, $13.6 \%$ are meritocratic, and $29.4 \%$ are libertarian. ${ }^{14}$ The analysis using only the initial offers yields a slightly higher fraction of libertarian and egalitarian offers, leaving the results qualitatively unchanged. Looking at the final accepted offers the picture is quite similar to the one when we consider all offers made. Compared to the initial offers the partners move towards less extreme outcomes (more choice egalitarian or more meritocratic). This result is quite intuitive. The more selfish initial offers cannot be achieved since the final (accepted) offer is more generous to the other partner. It is remarkable that the distribution of fairness ideal found in the offers is quite different from the distribution in subjects (compare Tables 2, 3). In particular, we observe a much smaller share of meritocratic offers than subjects with meritocratic fairness ideals. Instead there is a rather large share of egalitarian offers. This suggests that subjects do not always make offers based on what they considered fair in the pre-experimental questionnaire.

\footnotetext{
Footnote 13 continued

The results can be found in Figure B2 and Table B5 in the Online Appendix. A minority of participants in this survey group perceived the "brain teaser" to depend mostly on effort. While this does not affect our main results this means that a minority of subjects classified as meritocrats might actually be choice egalitarians.

14 Note that these shares refer only to claims that can be classified uniquely. In many cases an offer in a particular case is consistent with several fairness ideals. In all cases, in which the contributions of the two partners are identical, no matter how they were produced, the egalitarian and the libertarian distribution are identical. 201 out of 705 offers $(28.5 \%)$ can be uniquely assigned to one fairness ideal. The share of all uniquely classified initial offers is $23.3 \%$.
} 
Table 3 Classification of offers

\begin{tabular}{|c|c|c|c|c|c|}
\hline & \# & Egalitarian & Choice egalitarian & Meritocratic & Libertarian \\
\hline All offers & 201 & $28.9 \%$ & $27.9 \%$ & $13.9 \%$ & $29.4 \%$ \\
\hline Lower contribution & 113 & $44.2 \%$ & $29.2 \%$ & $11.5 \%$ & $15.0 \%$ \\
\hline Higher contribution & 85 & $9.4 \%$ & $27.1 \%$ & $14.1 \%$ & $49.4 \%$ \\
\hline $\begin{array}{l}\text { Difference high vs. low (p } \\
\text { value) }\end{array}$ & & $<0.001$ & 0.742 & 0.586 & $<0.001$ \\
\hline All initial offers & 56 & $35.7 \%$ & $16.1 \%$ & $5.4 \%$ & $42.9 \%$ \\
\hline Lower contribution & 33 & $51.5 \%$ & $21.2 \%$ & $3.0 \%$ & $24.2 \%$ \\
\hline Higher contribution & 23 & $13.0 \%$ & $8.7 \%$ & $8.7 \%$ & $69.6 \%$ \\
\hline $\begin{array}{l}\text { Difference high vs. low (p } \\
\text { value) }\end{array}$ & & 0.001 & 0.108 & 0.182 & $<0.001$ \\
\hline All accepted offers & 58 & $24.1 \%$ & $31.0 \%$ & $12.1 \%$ & $32.8 \%$ \\
\hline Lower contribution & 31 & $29.0 \%$ & $25.8 \%$ & $12.9 \%$ & $32.3 \%$ \\
\hline Higher contribution & 26 & $19.2 \%$ & $38.5 \%$ & $07.7 \%$ & $34.6 \%$ \\
\hline $\begin{array}{l}\text { Difference high vs. low (p } \\
\text { value) }\end{array}$ & & 0.201 & 0.157 & 0.266 & 0.427 \\
\hline
\end{tabular}

The table is based on all offers of all subjects, i.e. both from the treatments with and without the preexperimental questionnaire. The numbers reported are the shares of offers that can be classified as fair according to one of the fairness ideals. In many cases, offers are fair according to several fairness ideals. The table contains only those offers that can be classified uniquely according to least-squared deviation from one of the fairness ideals. The differences between offers are tested using one-sided t tests

\subsubsection{High vs. low contributors}

An obvious factor that might affect offers is the proposer's own contribution to the joint surplus measured by total earnings from the production phase compared to the contribution of the bargaining partner. If we group subjects according to whether they contributed less or more than the partner we see that there are significant differences. Subjects with lower contributions make significantly more egalitarian offers than those with higher contributions and also make significantly fewer libertarian offers. The most frequent offer of subjects with lower earnings is the egalitarian offer (44.2\%) and the most frequent offer of the high-contributors is the libertarian offer (49.4\%). Using only the initial offers this pattern becomes even stronger with more than $50 \%$ egalitarian offers from the low contributors and almost $70 \%$ of libertarian offers by the high contributors. These findings can be explained by the fact that these offers are the most beneficial for the proposer in the respective situations.

\subsubsection{Type-consistency}

One central question of our paper is whether the offers in the bargaining are consistent with the type elicited in the questionnaire. In order to answer this question, we estimate the coefficients in Eq. (7). In the theory section we argued that following the respective fairness ideals imposes restrictions on the weights with which the different income components of the two partners enter the offer of the subject that makes a proposal. 
If the subjects' behaviour is influenced by the fairness considerations stated in the questionnaire, we expect the estimated weights on the income components from the production phase to be close to the theoretical ones that are summarised in Table 1. We estimate Eq. (7) for the subject who makes the offer (we call this subject the proposer) and their respective partner for each fairness type. Table 4 contains the estimated weights for the three fairness types individually and for all types together from OLS regressions using all offers. ${ }^{15}$ Almost all estimated weights deviate significantly from the theoretical predictions and F-tests show that no group makes offers that are on average consistent with the elicited fairness ideals. In fact, the estimated weights are very similar across the groups which is also confirmed by the regression with all subjects in column (4). For the subject's own income components, the estimated weights are between 0.68 and 0.97 and for the incomes of the partner they range from 0.03 to 0.32 .

As shown in Table 3, subjects make different types of offers depending on their relative contribution to the total surplus in a bargaining pair. We hence repeat the previous regressions for proposers with lower contributions than the partner and for proposers with higher contributions separately. The regression results can be found in table B2 in the Online Appendix. This analysis confirms that the size of the proposer's contribution to the joint surplus relative to the contribution of the partner has an impact on the initial offers. For all fairness ideals the estimated coefficients are significantly different between the two groups $(\mathrm{p}<0.01, \mathrm{~F}$-test). Subjects with higher contributions than their partner tend to claim most of their own income and little of the partner's income.

The offers of the choice egalitarians are libertarian, those of the meritocrats are in fact meritocratic, and the ones of the libertarians almost libertarian. The lowperforming subjects, however, want to keep less of their own (lower) income and claim higher fractions of the partner's (higher) income. They claim between $64 \%$ and $87 \%$ of the proposer's own income components and between $13 \%$ and $36 \%$ of the partner's. In no case, the estimated weights fit to one of the four accountabilitybased fairness ideals. In fact, only for high-contributing meritocrats, we can reject the hypothesis that all weights on the three source of one's own income are equal (F-test, $\mathrm{p}<0.001$ ). In all other cases, the coefficients are not statistically different from each other at conventional levels. When making offers, what seems to matter most is whether a subject's own contribution was higher or lower than the one of their partner; and not what fairness ideals they ascribe to. When pooling all types in columns (7) and (8), we find that no matter of the how the income was produced, the low performers claim about $75 \%$ of their own contribution and $25 \%$ of their partner's. The high performers behave like libertarians and want to keep all of their own contribution.

\footnotetext{
15 We restricted the coefficient of the own income component and that of the partner to sum up to one in line with the theoretical weights in Table 1. In regressions without this constraint, the results are very similar and do not change any conclusions. Using only the first or the accepted offers we get similar results and none of our conclusions change.
} 
Table 4 Estimation of weights on contributions, all offers

\begin{tabular}{|c|c|c|c|c|c|c|c|}
\hline & \multicolumn{2}{|l|}{ (1) } & \multicolumn{2}{|l|}{ (2) } & \multicolumn{2}{|l|}{ (3) } & \multirow{2}{*}{$\begin{array}{l}\text { (4) } \\
\text { All types }\end{array}$} \\
\hline & \multicolumn{2}{|c|}{ Choice egalitarian } & \multicolumn{2}{|l|}{ Meritocratic } & \multicolumn{2}{|l|}{ Libertarian } & \\
\hline & Theoretical & Estimate & Theoretical & Estimate & Theoretical & Estimate & Estimate \\
\hline \multicolumn{8}{|l|}{ Own } \\
\hline$Y_{\mathrm{i}}^{\text {effort }}$ & 1 & $\begin{array}{l}0.97 \\
\quad(0.04)\end{array}$ & 1 & $\begin{array}{r}0.87^{++} \\
(0.02)\end{array}$ & 1 & $\begin{array}{c}0.81^{++} \\
(0.04)\end{array}$ & $0.86(0.02)$ \\
\hline $\mathrm{Y}_{\mathrm{i}}^{\text {talent }}$ & 0.5 & $\begin{array}{c}0.89^{++} \\
(0.04)\end{array}$ & 1 & $\begin{array}{c}0.86^{++} \\
(0.02)\end{array}$ & 1 & $\begin{array}{l}0.85^{++} \\
(0.03)\end{array}$ & $0.85(0.02)$ \\
\hline $\mathrm{Y}_{\mathrm{i}}^{\text {luck }}$ & 0.5 & $\begin{array}{l}0.76^{++} \\
\quad(0.07)\end{array}$ & 0.5 & $\begin{array}{r}0.68^{++} \\
(0.04)\end{array}$ & 1 & $\begin{array}{l}0.85 \\
\quad(0.10)\end{array}$ & $0.82(0.04)$ \\
\hline \multicolumn{8}{|l|}{ Partner } \\
\hline $\mathrm{Y}_{\mathrm{k}}^{\mathrm{effort}}$ & 0 & $\begin{array}{l}0.03 \\
\quad(0.04)\end{array}$ & 0 & $\begin{array}{c}0.13^{++} \\
(0.02)\end{array}$ & 0 & $\begin{array}{c}0.19^{++} \\
(0.04)\end{array}$ & $0.14(0.02)$ \\
\hline $\mathrm{Y}_{\mathrm{k}}^{\text {talent }}$ & 0.5 & $\begin{array}{r}0.11^{++} \\
(0.04)\end{array}$ & 0 & $\begin{array}{r}0.14^{++} \\
(0.02)\end{array}$ & 0 & $\begin{array}{c}0.15^{++} \\
(0.03)\end{array}$ & $0.15(0.02)$ \\
\hline $\mathrm{Y}_{\mathrm{k}}^{\text {luck }}$ & 0.5 & $\begin{array}{l}0.24^{++} \\
(0.07)\end{array}$ & 0.5 & $\begin{array}{c}0.32^{++} \\
(0.04)\end{array}$ & 0 & $\begin{array}{l}0.15 \\
\quad(0.10)\end{array}$ & $0.18(0.04)$ \\
\hline Const & 0 & $\begin{array}{c}0.89^{++} \\
(0.16)\end{array}$ & 0 & $\begin{array}{c}0.49^{++} \\
(0.13)\end{array}$ & 0 & $\begin{array}{c}0.85^{++} \\
(0.19)\end{array}$ & $0.76(0.07)$ \\
\hline Adj. $R^{2}$ & & 0.870 & & 0.823 & & 0.919 & 0.870 \\
\hline \multicolumn{8}{|l|}{ F-test } \\
\hline $\mathrm{P}$ & & $<0.001$ & & $<0.001$ & & $<0.001$ & \\
\hline \# & & 127 & & 186 & & 131 & 601 \\
\hline
\end{tabular}

Constrained OLS regression, adj. $\mathrm{R}^{2}$ refers to the estimation with unconstrained coefficients, F-test refers to F-test on the difference of the estimators from the theoretically predicted weights. The standard errors in parenthesis are clustered at the bargaining-group level

${ }^{++},+$Significant difference from theoretical value at $1 \%, 5 \%$ level

\subsubsection{Best fair offers}

We claimed above, that fairness may play a functional role in bargaining. Subjects might behave purely out of self-interest, but the bargaining will be successful only if both sides agree and consider the outcome fair. It might hence be less relevant what each bargaining partner would consider fair as an impartial spectator than what can be justified as fair in the process of bargaining. If this is the case, subjects' offers will not be strongly related to their own fairness ideals. They rather might use the best fair offer in each case, which we define as the one of the four different fair offers, which gives the proposer the highest monetary payoff. Thus the same subject might argue that the equal split is fair, if he is in the disadvantaged position, but make the libertarian offer, if he contributed more than another partner. 
Table 5 Classification of offers-type-consistent offer versus best fair offers

\begin{tabular}{lcrll}
\hline Offer & Obs & Share & Difference & $p$ \\
\hline All initial & 182 & & & \\
(1) Type-consistent & & $33.0 \%$ & & \\
(2) Best & & $56.6 \%$ & & \\
(3) Conflict & & $72.0 \%$ & & \\
(4) Low contribution & & $38.5 \%$ & & \\
(5) High contribution & & $51.7 \%$ & & \\
With conflict & 131 & & & \\
(6) Type-consistent & & $18.3 \%$ & & \\
(7) Best & & $51.1 \%$ & $(7)>(6)$ & \\
With conflict, low & 58 & & & \\
$\quad$ contribution & & & & \\
(8) Type-consistent & & $32.8 \%$ & & \\
(9) Best & & $6.9 \%$ & $(9)<(8)$ & $<0.001$ \\
With conflict, high & 61 & & & \\
$\quad$ contribution & & $3.3 \%$ & & \\
(10) Type-consistent & & $91.8 \%$ & $(11)>(10)$ & $<0.001$ \\
(11) Best & & & & \\
\hline
\end{tabular}

One-third of all initial ${ }^{16}$ offers are consistent with the fairness ideal ("type") of the proposer as measured by the pre-experimental questionnaire, while slightly more than half $(56.6 \%)$ of the initial offers are best fair offers (see Table 5). Comparing these two shares is not very informative, however, because in $28 \%$ of the cases there is no conflict between the best fair offer and the type-consistent offer. If the best fair offer and the type-consistent offer are identical, $70.6 \%$ of the offers are type-consistent.

The relevant test case for opportunism occurs when there is a conflict between the best fair offer and the type-consistent offer. In the 131 cases of conflict the share of type-consistent offers is $18.3 \%$ and the share of best fair offers is $51.1 \%$, which is significantly larger $\left(\mathrm{p}<0.02, \chi^{2}\right.$ test). We can split up this sample further in the group of proposers with lower contributions than the partner and the group with higher contributions. Of the proposers with low contributions, $32.8 \%$ follow their fairness ideal, $6.9 \%$ make best fair offers and the majority does something in between. Those subjects that earned more in the real-effort task than their respective partners choose the best fair offer in $91.8 \%$ of the cases in which it is different from their type-consistent offer. Only $3.3 \%$ act upon their fairness ideal.

These opportunistic patterns can also be analysed linking the relative contribution to the overall surplus to the claim in the bargaining process. In Online Appendix B we provide a more detailed analysis of the bargaining process. We find that subjects with low total earnings in general demand more than their contribution and that there is a gender-bias in that men demand higher shares of the surplus than women.

\footnotetext{
16 We use the initial claims for this analysis, as these might reflect subjects' intentions best. The first offers are not influenced by offers of the partner or previous offers of the proposer.
} 
Summing up, we find that subjects hold fairness ideals that can be classified as choice egalitarian, meritocratic or libertarian. Almost $75 \%$ of all subjects are either meritocrats or libertarians when they are impartial spectators and make fairness judgments about other people. No subject displayed an egalitarian ideal. When the subjects bargain about their own monetary payoff, however, their behaviour is rarely consistent to the stated fairness ideals. Almost irrespective of the ideals as impartial spectators, subjects claim almost all of the own income if they produced more than their partner, and claim a significant share of the partner's total income if they produced less. This is clear evidence of opportunistic behaviour.

\subsection{Bargaining outcomes}

In order to test the fairness-augmented Nash model, we regress the offer of subjects $i$ in bargaining round $r$ on the total surplus $Y$ and on the fairness ideals of the two partners in the respective round:

$$
x_{i r}=\beta_{0}+\beta_{1} Y_{r}+\beta_{2} x_{i r}^{f}+\beta_{3} x_{j r}^{f}+\varepsilon_{i r}
$$

Since the Nash solution refers to the final outcome of the bargaining, we only use the accepted offers in this OLS regression.

According to Eqs. (3) and (4), the constant in this regression should be zero, and $\beta_{1}=\frac{\phi_{i}}{\phi_{i}+\phi_{j}}, \beta_{2}=\frac{\phi_{j}}{\phi_{i}+\phi_{j}} \mu_{i}$, and $\beta_{3}=-\frac{\phi_{i}}{\phi_{i}+\phi_{j}} \mu_{j}$. Obviously, we have four structural parameters $\phi_{i}, \phi_{j}, \mu_{i}$ and $\mu_{j}$, but only three estimated coefficients $\beta_{1}, \beta_{2}$, and $\beta_{3}$ so that we cannot identify the structural parameters without additional assumptions. We proxy the bargaining power parameter $\phi$. Asymmetric bargaining power might result from potential differences in risk aversion. We measured risk attitude by the answers to the question: "Are you generally a person who is fully prepared to take risks or do you try to avoid taking risks?" The possible answers range from 0 (completely unwilling to take risks) to 10 (completely willing). Using a large micro-data set, Dohmen et al. (2011) validated this general risk attitude question and found that it is strongly correlated with standard experimental procedures to elicit risk attitudes. For each subject, we simply equate $\phi$ with the score from the risk attitude question so that we can compute $\frac{\phi_{1}}{\phi_{1}+\phi_{2}}$ and $\frac{\phi_{2}}{\phi_{1}+\phi_{2}}$ for each bargaining group. We then adjust the regressors for the computed measures of bargaining power resulting from differences in risk attitudes. In the estimations using these risk-adjusted regressors the coefficient on the total surplus $\mathrm{Y}$ should be equal to one and the coefficients on the risk-adjusted fair offers are theoretically equal to $\mu_{1}$ and $\mu_{2}$.

Another issue is which fairness ideals to use to compute the regressors $x_{i r}^{f}$ and $x_{j r}^{f}$. Again, we take two approaches and use statistical criteria to determine the better one. The first and obvious approach is to use the fairness ideals elicited from the questionnaire. In the preceding subsection, however, we argued that subjects do not make offers according to their fairness ideal from the questionnaire, but rather behave opportunistically. In Table 5, we showed that the subjects with the larger contributions in a pair claim everything they contributed while the subjects with the smaller contribution claim about three quarters of their own contribution and one quarter of the 
Table 6 Estimation of the parameters in the fairness-augmented Nash bargaining solution

OLS regressions, $\mathrm{p}$ values of $\mathrm{t}$ test on respective hypothesis

\begin{tabular}{lll}
\hline & $(1)$ & $(2)$ \\
& Fair & Opportunistic \\
\hline Constant & $0.045(0.418)$ & $-0.248(0.358)$ \\
$\mathrm{Y}$ & $0.864 * * *(0.027)$ & $1.046^{* * *}(0.030)$ \\
$x_{1}^{f}$ & $1.003^{* * *}(0.026)$ & $0.989^{* * *}(0.022)$ \\
$x_{2}^{f}$ & $-0.704 * * *(0.055)$ & $-1.023^{* * *}(0.059)$ \\
Adj R & 0.945 & 0.962 \\
BIC & 521.45 & 457.37 \\
RMSE & 1.024 & 0.852 \\
$\#$ & 175 & 175 \\
$\mathrm{p}\left(\beta_{2}=-\beta_{3}\right)$ & $<0.001$ & 0.637 \\
$\mu$ & {$[0.704,1.003]$} & {$[0.989,1.02]$} \\
\hline
\end{tabular}

partner's earnings. Running an OLS regression of all offers of the low-performers on their own total income and the partner's total income as regressors and constraining the two coefficients to sum to one yields a coefficient of 0.733 on own income and 0.267 on the partner's income. We hence use these coefficients to calculate the opportunistic offers of those who contribute little and assume that the high-contributors demand their full contribution in our second approach.

Table 6 shows the estimation results. The BIC suggests that the model with the opportunistic fairness ideals in column (2) is better than the model with the fairness ideals derived from the questionnaire. In the opportunistic model, the coefficient on $Y$ is not different from one and we cannot reject that $\beta_{2}=-\beta_{3}$, meaning that $\mu_{1}=\mu_{2}=$ $\mu$. The implied values for $\mu$ are between 0.989 and 1.023 . Running another regression with the constraint that the coefficients be equal yield an estimate of $\mu=0.99$, which is consistent with the theoretical assumption. The BIC of the constrained estimation is 452.44 , which is slightly better than the BIC of the unconstrained model.

We conclude that the fairness-augmented Nash solution is a valid description of the bargaining outcomes in our experiment, if the appropriate fair offers are used. As the analysis in Sect. 4.1 suggests, subjects do not act upon the stated fairness ideals but behave in a rather opportunistic way. Subjects with larger contributions are well described by the assumption that they want to keep their own total contribution, while those with smaller contributions want to keep about three quarters of their own earnings and claim about one quarter of the partner's income.

\section{Conclusion}

In this paper we analysed unstructured bargaining after individual production of a joint surplus. In particular, we investigated whether subjects' offers depended on their respective contributions to the surplus and how fairness affects both offers in, and outcomes of the bargaining process. We operationalised fairness by fairness ideals 
based on theories of justice and distinguished between them according to the principle of individual accountability.

We found that as impartial, neutral observers none of our 72 subjects consider egalitarian allocations of a jointly produced surplus fair. As expected, the egalitarian distribution is not expected to be fair once the individual contributions to the surplus are known. $26.4 \%$ of subjects favour choice egalitarian distributions, but the majority states that the libertarian distribution $(29.2 \%)$ or the meritocratic distribution (44.4\%) are fairest. While we find shares of meritocrats and libertarians that are very similar to those reported in Cappelen et al. (2010)—-meritocrats $47 \%$ and libertarians 30.1\% - those authors report a significant share of strict egalitarians of $18 \%$ and only a small share of choice egalitarians of $4.6 \%$. This difference might be due to the different methods to determine subjects' fairness ideals. The dictator game that is used in Cappelen et al. (2010) could either make the egalitarian division of the surplus very salient or make some subjects believe that they are compelled to make egalitarian offers as argued in Dana et al. (2007). A questionnaire before the bargaining might bring to subjects' attention that distributions other than the equal split can be regarded as fair, especially if subjects have to choose from several available options. This is also what Cappelen et al. (2011) find. To investigate whether moral reflection matters in experiments, Cappelen et al. (2011) use an elicitation question before the production phase. In this question they ask subjects to state their preferred fairness ideals. They find that the share of self-reported strict egalitarians before the production phase is $9.8 \%$. In a base treatment (the treatment in which they do not ask the subjects about their fairness ideal), they estimate that the share of strict egalitarians is $43.5 \%$ compared to a point estimate of $20.2 \%$ in the treatment with moral reflection.

A further result is that subjects' elicited fairness ideals hardly matter for their bargaining behaviour. The offers of subjects with above-average earnings from the production phase are clearly centred around those earnings. On average the offers of the high-performers can be described quite well by the libertarian fairness ideal. Subjects with below-average earnings typically claim more than their contribution to the joint surplus. The offers are halfway between the egalitarian and the libertarian offer, i.e. they want to keep roughly $75 \%$ of their own contribution and claim $25 \%$ of the partner's earnings. Both sides' offers are evidence for opportunistic behaviour. The offers can still be justified as somehow fair, but they have a clear egocentric bias towards material self-interest. In a sense, the behaviour of the low-contributors is more modestly opportunistic than the behaviour of the high-contributors, since they do not go all the way to the most favourable egalitarian offer. The stark difference between subjects' fairness statements as impartial spectators and their opportunistic behaviour in the bargaining suggests that the equal bargaining power in our experiment (apart from potential differences in risk aversion) creates "moral wiggle room" that allows subjects to behave more selfishly than they would in more asymmetric situations such as the dictator game.

The theoretical contribution of this paper is to show that the standard Nash bargaining solution can be adjusted to incorporate fairness. With opportunistic fair offers derived from the observed offers, the model is able to explain $96 \%$ of the variation in the accepted offers. The estimations show that differences in risk attitudes of the two bargaining partners matter for the model predictions. 
Acknowledgements We would like to thank Anders Poulsen and Emin Karagözoğlu as well as two anonymous referees and the associate editor for very helpful comments and suggestions.

Open Access This article is distributed under the terms of the Creative Commons Attribution 4.0 International License (http://creativecommons.org/licenses/by/4.0/), which permits unrestricted use, distribution, and reproduction in any medium, provided you give appropriate credit to the original author(s) and the source, provide a link to the Creative Commons license, and indicate if changes were made.

\section{References}

Aumann RJ, Maschler M (1985) Game theoretic analysis of a bankruptcy problem from the Talmud. J Econ Theory 36:195-213

Babcock L, Loewenstein G (1997) Explaining bargaining impasse: the role of self-serving biases. J Econ Perspect 11:109-126

Birkeland S, Tungodden B (2014) Fairness motivation in bargaining: a matter of principle. Theor Decis 77(1):125-151

Bolton GE, Ockenfels A (2000) ERC: a theory of equity, reciprocity, and competition. Am Econ Rev 96(5):166-193

Cappelen AW, Hole AD, Sørensen EØ, Tungodden B (2007) The pluralism of fairness ideals: an experimental approach. Am Econ Rev 97(3):818-827

Cappelen AW, Sørensen EØ, Tungodden B (2010) Responsibility for what? Fairness and individual responsibility. Eur Econ Rev 54:429-441

Cappelen AW, Hole AD, Sørensen EØ, Tungodden B (2011) The importance of moral reflection and selfreported data in a dictator game with production. Soc Choice Welf 36:105-120

Dana J, Weber R, Kuang JX (2007) Exploiting moral wiggle room: experiments demonstrating an illusory preference for fairness. Econ Theor 33:67-80

Dohmen T, Falk A, Huffman D, Sunde U, Schupp J, Wagner GG (2011) Individual risk attitudes: measurement, determinants, and behavioural consequences. J Eur Econ Assoc 9(3):522-550

Fehr E, Schmidt KM (1999) A theory of fairness, competition, and cooperation. Q J Econ 114(3):817-868

Fischbacher U (2007) z-Tree: Zurich toolbox for ready-made economic experiments. Exp Econ 10(2):171-178

Gächter S, Riedl A (2005) Moral property rights in bargaining with infeasible claims. Manag Sci 51(2):249-263

Gächter S, Riedl A (2006) Dividing justly in bargaining problems with claims. Soc Choice Welf 27:571-594

Hesse J, Schrader HC (2009) Test training 200 plus: Einstellungs- und Eignungstests erfolgreich bestehen. Stark Verlagsgesellschaft, New York

Karagözoğlu E (2012) Bargaining games with joint production. In: Croson R, Bolton G (eds) Handbook of economic conflict resolution. Oxford University Press, Oxford

Karagözoğlu E, Riedl A (2014) Information, uncertainty, and subjective entitlements in bargaining. Manage Sci 61(11):2611-2626

Konow J (1996) A positive theory of economic fairness. J Econ Behav Organ 31(1):13-35

Konow J (2000) Fair shares, accountability and cognitive dissonance in allocation decisions. Am Econ Rev 90:1072-1092

Konow J (2001) Fair and square: the four sides of distributive justice. J Econ Behav Organ 46(2):137-164

Konow J (2003) Which is the fairest one of all? A positive analysis of justice theories. J Econ Perspect 61:1188-1239

Nash JF (1950) The bargaining problem. Econometrica 50(1):97-109

Rustichini A, Villeval MC (2014) Moral hypocrisy, power and social preferences. J Econ Behav Organ 107:10-24

Publisher's Note Springer Nature remains neutral with regard to jurisdictional claims in published maps and institutional affiliations. 


\section{Affiliations}

Wolfgang J. Luhan ${ }^{1}$ - Odile Poulsen ${ }^{2} \cdot$ Michael W. M. Roos ${ }^{3}$

Michael W. M. Roos

Michael.Roos@ruhr-uni-bochum.de

1 Economics and Finance Subject Group, Faculty of Business and Law, University of Portsmouth, Richmond Building, Portland Street, Portsmouth PO13DE, UK

2 School of Economics, University of East Anglia, Norwich NR4 7TJ, UK

3 Institute for Macroeconomics, Faculty of Management and Economics, Ruhr-Universität Bochum, Universitätsstrasse 150, 44801 Bochum, Germany 